\title{
BMJ Open Geriatrician-led evidence-based Falls Prevention Clinic: a prospective 12-month feasibility and acceptability cohort study among older adults
}

\author{
Jennifer C Davis, ${ }^{1}$ Larry Dian, ${ }^{2,3,4}$ Naaz Parmar, ${ }^{4}$ Kenneth Madden, ${ }^{4}$ \\ Karim M Khan, ${ }^{2,3,5}$ Wency Chan, 2,6,7 Winnie Cheung, ${ }^{2,7,6}$ Jessica Rogers, ${ }^{2}$ \\ Teresa Liu-Ambrose $2,7,6$
}

To cite: Davis JC, Dian L, Parmar N, et al. Geriatricianled evidence-based Falls Prevention Clinic: a prospective 12-month feasibility and acceptability cohort study among older adults. BMJ Open 2018;8:e020576. doi:10.1136/ bmjopen-2017-020576

- Prepublication history for this paper is available online. To view these files, please visit the journal online (http://dx.doi. org/10.1136/bmjopen-2017020576).

Received 24 April 2018 Revised 12 October 2018 Accepted 25 October 2018
Check for updates

(C) Author(s) (or their employer(s)) 2018. Re-use permitted under CC BY-NC. No commercial re-use. See rights and permissions. Published by BMJ.

For numbered affiliations see end of article.

Correspondence to Dr Jennifer C Davis; jennifer.davis@ubc.ca

\section{ABSTRACT}

Objective We assessed the feasibility and acceptability of delivering a geriatrician-led evidence-based Falls Prevention Clinic to older adults with a history of falls. Design 12-month prospective cohort study.

Setting Vancouver Falls Prevention Clinic, Vancouver, British Columbia, Canada (www.fallsclinic.ca).

Participants 188 community-dwelling older adults aged $\geq 70$ years who received a baseline assessment at the Vancouver Falls Prevention Clinic due to having had at least one fall resulting in medical attention in the previous 12 months. Fifty-six per cent of participants were also participating in a randomised controlled trial.

Measurements Feasibility was ascertained by measuring demand (clinic attendance). Acceptability was measured by compliance with recommendations, completion of monthly fall calendars and patient experience.

Results The attendance was $65 \%$ of those eligible and invited. This indicates feasibility for demand. 155 received at least one of the following clinical management recommendations from four domains (compliance reported in \%): (1) medication changes (78\%); (2) exercise prescription (58\%); (3) referrals to other healthcare professionals (78\%); and/or (4) lifestyle modifications (35\%) excluding exercise. Overall compliance to all recommendations was $69 \%$. Patient experience was related to factors impacting patient perceived physical benefit and attributes influencing patient satisfaction. Conclusion This study demonstrated the feasibility and acceptability of a multifactorial intervention approach based on best available evidence-based medicine.

\section{INTRODUCTION}

Falls are a common geriatric syndrome ${ }^{1}$ and are a leading cause of chronic disability from injury and mortality worldwide. ${ }^{23} \mathrm{In}$ 2014, up to $28.7 \%$ of community dwellers over the age of 65 years experience one or more falls annually, ${ }^{3}$ resulting in 29 million falls. Of these, $37.5 \%$ required medical treatment or resulted in activity restrictions and approximately 33000 deaths were attributed to falls in 2015 . $^{3}$

\section{Strengths and limitations of this study}

- This study contains novel qualitative data on patient perceptions of the falls clinic experience. These perceptions provide useful knowledge that can be applied for improving patient compliance and subsequent health outcomes.

- The measures used in this study are research quality measurements that confirmed study participants were at high risk for falls complementing the inclusion criteria used in this and other studies of 'history of fall in past 12 months.'

- This study did not report fall-related outcome data or effectiveness of the Falls Prevention Clinic intervention itself given this was not a randomised controlled trial.

Implementing a single-factor falls prevention intervention may prevent approximately 9500 to 45000 medically treated falls and thus save \$94-\$442 million in direct medical costs annually depending on the size of the population. ${ }^{4}$ As the proportion of older adults increases, falls will place an increasing demand and cost on the public health system. The good news is that several effective and cost-effective strategies exist to prevent falls. ${ }^{56}$

Multifactorial falls prevention strategies can be cost-effective and cost saving in preventing falls. ${ }^{67}$ A multifactorial intervention or prevention strategy consists of multiple components that all aim to mitigate the risk factors for falling identified by a person's individual multifactorial assessment. A meta-analysis published in 2004 reported that a multifactorial fall risk assessment and management programme reduced falls among older adults regardless of their fall risk profile (low or high). ${ }^{8}$ However, a 2012 Cochrane systematic 
review concluded that multifactorial interventions were effective among older adults only if the participants had a history of falling or other fall risk factors. ${ }^{6}$ One way to deliver multifactorial falls prevention to high-risk patients is via a medical clinic dedicated to falls prevention. Such a clinic setting was evaluated in the hallmark Prevention of Falls in the Elderly Trial study; a multifactorial individually tailored intervention led by a geriatrician reduced falls by approximately $60 \% .^{9}$ There is growing efficacy and effectiveness evidence demonstrating that various analogues of falls prevention clinics can reduce falls and injurious falls, and improve activities of daily living among high-risk groups. ${ }^{10-14}$ Of these, a Finnish randomised controlled trial (RCT) that tested a multifactorial individually tailored falls clinic service demonstrated a $26 \%$ reduction in falls and fall-related injuries. ${ }^{14}$

Despite successful examples of the multifactorial approach to falls prevention, the efficacy (controlled research setting) and effectiveness (real-world trial setting) evidence for such an approach remains unknown. By definition, efficacy trials (ie, an RCT) examine whether an intervention results in the expected outcome under ideal and controlled circumstances that minimise all known sources of bias. Effectiveness trials take place under 'real world' conditions and measure the benefit of the intervention. Feasibility hinges on starting with an intervention with demonstrated efficacy and ideally effectiveness and brings together other elements such as demand (ie, attendance), acceptability (ie, compliance) and patient experience to determine whether the intervention is possible.

Dimensions of the concept of feasibility may explain some of the inconsistent findings in the literature relating to the use of a multifactorial approach for falls prevention. ${ }^{15}$ Feasibility comprised several factors and these factors also impact efficacy and effectiveness. These include: (1) demand assessed in part through attendance rate, (2) acceptability as assessed through compliance, and (3) patient experience. A few factors that likely contribute a critical role specifically in the observed feasibility of multiple recommendations received using a multifactorial approach to falls prevention in a falls clinic setting are: (1) staffing structure of healthcare professionals (ie, geriatrician, general practitioner, nurse) and training of healthcare professionals who comprise the falls prevention clinics, and (2) patient attendance with appointments and compliance to the clinic visits and recommendations.

Therefore, we conducted a cohort study to assess the feasibility and acceptability of delivering a geriatrician-led Falls Prevention Clinic to older adults with a history of falls (ie, a high-risk group). Specifically we assessed feasibility by measuring: (1) demand (ie, attendance) and (2) acceptability by measuring overall and domain-specific compliance, completion of monthly fall calendars and patient experience with the Vancouver Falls Prevention Clinic service. Of note, domain-specific compliance was based on the following five categories of clinical management advice provided: (1) medication, (2) exercise, (3) consultations/referrals, (4) lifestyle, and (5) total combined compliance.

\section{METHODS}

\section{Study design}

We conducted a 12-month prospective cohort study at the Vancouver Falls Prevention Clinic (www.fallclinic.com) from September 2010 through August 2015. Of note, $56 \%$ participants in the cohort study were also participating in an RCT aimed at secondary falls prevention. ${ }^{16}$ Participants in the intervention arm of the RCT received a home-based exercise programme for 12 months called the Otago Exercise Programme (OEP). ${ }^{17}$

\section{Participants and setting}

The sample consisted of 188 women and men referred by their general practitioner or emergency department physician to the Vancouver Falls Prevention Clinic with complete data across the variables of interest in this study. Inclusion and exclusion criteria for the Vancouver Falls Prevention cohort are previously described. ${ }^{18} 19$ Briefly, community-dwelling women and men who lived in the lower mainland region of British Columbia were eligible to be seen at the Vancouver Falls Prevention Clinic and thus eligible for study entry if they were adults $\geq 70$ years of age referred by a medical professional to the Falls Prevention Clinic as a result of seeking medical attention for a non-syncopal fall in the previous 12 months and were able to provide written informed consent.

The inclusion criteria (ie, previous fall in the past 12 months) were specifically selected to assist in identifying individuals at high risk of sustaining future falls. The US Task Force Guidelines recommend a multifactorial approach to falls prevention selectively among high-risk groups. ${ }^{3}$

We excluded those with a formal diagnosis confirmed by a physician of neurodegenerative disease (eg, Parkinson's disease) or dementia, patients who recently had a stroke, those with clinically significant peripheral neuropathy or severe musculoskeletal or joint disease and anyone with a history indicative of carotid sinus sensitivity (ie, syncopal falls).

Geriatrician-led multifactorial individually tailored assessment at the Vancouver Falls Prevention Clinic

All participants provided written informed consent to participate in Vancouver Falls Prevention Clinic cohort study and to be approached for other future studies related to falls.

All participants received a comprehensive medical examination to identify their individual risk factors for falls and fall-related injuries. A geriatrician assistant completed 
questionnaires and various functional, mobility, balance, strength and cognitive assessments described below. A geriatrician performed a comprehensive 1 hour medical check-up. The following factors were all reviewed as part of the geriatrician assessment: comprehensive medical exam, physical function, functional ability, physical activity/exercise (ie, strength and balance retraining), nutrition, medication review, alcohol/smoking review and a home hazard assessment. These follow the approach detailed by Palvanen et al. ${ }^{14}$

\section{Patient and public involvement}

Patients were not involved in the development of the research question, study design, recruitment or dissemination of the findings. Patients were involved in the qualitative research arm of this study and had the opportunity to provide feedback about their experience as a patient at the Vancouver Falls Prevention Clinic.

\section{Measures}

Primary outcome measure: feasibility

Feasibility was ascertained by measuring (1) demand (ie, attendance) and (2) acceptability (ie, compliance, return of monthly fall calendars and patient experience) with the Vancouver Falls Prevention Clinic service. We conducted semistructured individual interviews to gain an in-depth understanding of participants' experiences with the Vancouver Falls Prevention Clinic among a convenience subsample of participants.

\section{Descriptive variables}

We report the following descriptive measures relating to falls, balance and mobility, cognitive function, activities of daily living, mood and compliance to recommendations from the Vancouver Falls Prevention Clinic. These measurements were collected at baseline at the individual's index visit to the Vancouver Falls Prevention Clinic.

\section{Falls}

Ascertainment of falls was documented via monthly calendars, which were returned in prepaid and addressed envelopes at the end of each month. Participants were instructed to write the letter ' $F$ ' on days they experienced a fall. Falls were defined as 'unintentionally coming to the ground or some lower level and other than as a consequence of sustaining a violent blow, loss of consciousness, sudden onset of paralysis as in stroke or an epileptic seizure. ${ }^{20}$ Falls were prospectively recorded over the 12-month observation period.

\section{Balance and mobility}

Mobility and balance were assessed using the Short Physical Performance Battery ${ }^{21}$ and the Timed Up and Go (TUG) test. ${ }^{22}$

\section{Physiological falls risk}

Physiological falls risk was assessed using the short form of the Physiological Profile Assessment (PPA) that has a $75 \%$ predictive accuracy for falls in older people. ${ }^{2324}$ The
PPA provides a valid and reliable estimate of future falls risk. A PPA z-score of $0-1$ indicates mild risk of falling in the next 12 months, 1-2 indicates moderate risk, 2-3 indicates high risk, and 3 and above indicates marked risk. ${ }^{25}$

\section{Global cognitive function}

We assessed global cognition using the Mini-Mental State Examination (MMSE) and the Montreal Cognitive Assessment (MoCA). The MMSE and the MoCA (a screening tool for mild cognitive impairment (MCI)) are scored on a 30-point scale. ${ }^{2627}$

\section{Executive functions}

Within the multiple domains of cognition, reduced executive functioning is associated with falls ${ }^{28-32}$ and with increased risk of a major fall-related injury. ${ }^{33}$ There is no single test of unitary executive function-rather, there are distinct processes, including selective attention and response inhibition, set shifting and working memory. We used: (1) the Stroop Test ${ }^{34}$ to assess selective attention and response inhibition; (2) the Trail Making Test (parts A and B) to assess set shifting (ie, B-A) ${ }^{35}$; and (3) the Digit Symbol Substitution Test to assess working memory and processing speed. ${ }^{36}$

\section{Comorbidity, activities of daily living and depression}

Functional comorbidity index was calculated to estimate the number of comorbidities associated with physical functioning. ${ }^{37}$ We used the Lawton and Brody ${ }^{38}$ Instrumental Activities of Daily Living (IADL) scale to screen for impaired IADLs. We used the 15-item Geriatric Depression Scale S $^{39} 40$ to indicate the presence of depression; a score of $\geq 5$ indicates depression. ${ }^{41}$

\section{Compliance to recommendations}

All participants presenting to the Vancouver Falls Prevention Clinic were attended to by a geriatrician who provided individualised treatment plans that consisted of any of the following recommendations: (1) medication changes; (2) exercise prescription; (3) referrals to other healthcare professionals; and (4) lifestyle modifications. For all participants included in this study, all geriatrician recommendations made were recorded and participant compliance to these recommendations at follow-up (ie, 6 or 12 months) was recorded. We report compliance rates based on the four types of recommendations stated above as well as overall combined compliance.

\section{Statistical analyses}

\section{Assessment of feasibility and acceptability}

Feasibility was ascertained by measuring demand (ie, attendance). Acceptability was ascertained by measuring compliance, completion of monthly fall calendars and patient experience with the Vancouver Falls Prevention Clinic service.

To assess feasibility, we calculated demand (ie, the attendance). Attendance rate (\%) was defined as the number of eligible individuals who attended the baseline clinic appointment (numerator) divided by the number of total 
eligible participants invited to attend the baseline clinical appointment (denominator) $\times 100$.

A priori, we (operations, clinical and research managers) deemed the Vancouver Falls Prevention Clinic 'feasible' if the following conditions were achieved: completion of $70 \%$ return on falls prevention calendars and $<30 \%$ missing data overall. We calculated acceptability through reported overall and domain-specific per cent compliance to the following recommendations: (1) medication changes; (2) exercise prescription; (3) referrals to other healthcare professionals; and (4) lifestyle modifications. We also estimated compliance by reporting the per cent completion of monthly fall calendars. Lastly, we reported patient experience to summarise key themes identified from the semistructured interviews.

Acceptability was assessed in part through measuring the compliance of participants to (A) recommendations received from the Vancouver Falls Prevention Clinic and (B) completely their monthly fall calendars. We would deem the Vancouver Falls Prevention Clinic feasible if the following a priori thresholds were met: (1) $50 \%$ of the participants performed obtained $100 \%$ compliance in their domains and (2) if $50 \%$ of participants obtained $100 \%$ compliance in completing their monthly fall calendars. The choice of these thresholds was based on observed compliance from RCTs ${ }^{42}$ to achieve a desired effect size and from our previous feasibility work with the OEP. ${ }^{43}$

Data distributions for all descriptive data reported were initially examined using visual inspection of histograms and computation of skew and kurtosis values.

\section{Patient experience}

\section{Interview at study completion}

We conducted semistructured in-depth, open-ended follow-up interviews with participants in order to understand their experiences from attending the Vancouver Falls Prevention Clinic. We used three open-ended questions in each interview, designed to elicit responses about clinic satisfaction, benefits from the clinic and potential areas for improvement within the clinic. Participants were made aware that the purpose of the interview was to better understand their experiences from attending the clinic. Questions examined the following: (1) overall clinic experience; (2) benefits from the clinic; and (3) factors influencing their satisfaction with the clinic. We analysed the participant responses according to the three stages of qualitative analysis outlined by Carpenter and Suto ${ }^{44}$ : data reduction, data display and conclusion drawing/verification. Briefly, in the initial data reduction stage, two authors (JCD and TLA) repeatedly read participant responses from the interviews to highlight sections of data that informed the research question. We then clustered ideas together to form preliminary themes by two of the authors (JCD and TLA). We completed the conclusion drawing and verification stage and established a finalised set of overarching themes (JCD and TLA).
Table 1 Participant characteristics at baseline $(n=188)$

Frequency (\%) or mean

Variables (SD)

\begin{tabular}{|c|c|}
\hline Age (years) & $81(6)$ \\
\hline \multicolumn{2}{|l|}{ Sex } \\
\hline Male & $68(36.2)$ \\
\hline Female & $120(63.8)$ \\
\hline Height (cm) & $161(11)$ \\
\hline Weight (kg) & $69(16)$ \\
\hline \multicolumn{2}{|l|}{ Education } \\
\hline Grades $9-13$ or diploma & $8(4.2)$ \\
\hline High school & $14(7.4)$ \\
\hline Less than grade 9 & $11(5.9)$ \\
\hline University without certificate & $16(8.5)$ \\
\hline Trade or professional certificate & $18(9.6)$ \\
\hline University degrees & $41(21.8)$ \\
\hline Other & $80(42.6)$ \\
\hline IADL & $6.7(1.8)$ \\
\hline SPPB (12 points max) & $7.8(2.5)$ \\
\hline PPA & $2.6(1.3)$ \\
\hline TUG (s) & $17.3(7.5)$ \\
\hline GDS & $3.4(3.1)$ \\
\hline MMSE (30 points max) & $26.6(3.8)$ \\
\hline MoCA (30 points max) & $21.7(5.1)$ \\
\hline Stroop difference colour word & $83(45)$ \\
\hline Stroop 1 & $47.0(16.6)$ \\
\hline Stroop 2 & $74.7(28.1)$ \\
\hline Stroop 3 & $157.7(63.9)$ \\
\hline Trails B-A & $85(333)$ \\
\hline DSST & $20(7)$ \\
\hline
\end{tabular}

DSST, Digit Symbol Substitution Test; GDS, Geriatric Depression Scale; IADL, Instrumental Activities of Daily Living; MMSE, MiniMental State Examination; MoCA, Montreal Cognitive Assessment; PPA, Physiological Profile Assessment; SPPB, Short Performance Physical Battery; TUG, Timed Up and Go.

\section{RESULTS}

\section{Participants}

Participants enrolled in this study had a mean age of $81(\mathrm{SD}=6)$, with a mean baseline MoCA score of 21.7 $(\mathrm{SD}=5.1)$ and with scores of less than 26 indicative of MCI. ${ }^{35}$ The mean PPA score at baseline was $2.6(\mathrm{SD}=1.3)$, indicating marked falls risk (table 1 ). The mean TUG at baseline was $18.1(\mathrm{SD}=9.1)$.

\section{Assessment of feasibility}

Demand

Feasibility, ascertained by measuring attendance rate, was $65 \%$ at baseline.

Acceptability

Domain-specific and overall compliance

Of the 45 individuals who were prescribed medication changes, 35 (78\%) were $100 \%$ compliant. Of the 124 individuals who were prescribed exercise, $72(78 \%)$ were $58 \%$ 
compliant. Of the 40 individuals who received referrals to other healthcare professionals, $31(78 \%)$ were $100 \%$ compliant. Of the 17 individuals who were prescribed lifestyle modifications, $6(35 \%)$ were $100 \%$ compliant. Of the 42 individuals who were referred for additional tests or investigations, $36(86 \%)$ were $100 \%$ compliant. Of the 155 individuals who received at least one of the above four domains of recommendation, 93 (60\%) were $100 \%$ compliant to all recommendations. The overall compliance of all domains combined was $69 \%$.

To assess for the possibility of confounding of our compliance findings by inclusion of RCT participants, we reran our compliance analyses excluding the 54 participants in the intervention group of the RCT. The per cent compliance with most recommendations for the non-intervention participants was comparable to that of the full sample (table 2).

\section{Monthly falls calendar compliance}

Of the 188 individuals in this study, 170 (90\%) had $100 \%$ compliance on the completion of their monthly fall calendars. Of the 18 individuals who did not have $100 \%$ compliance, they were missing at least one of the 13 months of monthly falls data collected. On average, the per cent missing data for the first 9 months of data collection were $1 \%$. For the remaining last four collection periods, the per cent missing data ranged from $2 \%$ (months 1-10) to 7\% (month 13).

\section{Patient experience}

We identified two parent themes (box 1): (1) factors impacting patient perceived physical benefit from the Vancouver Falls Prevention Clinic, and (2) attributes influencing patient satisfaction with the Vancouver Falls Prevention Clinic. Factors impacting patient perceived physical benefit included: physical benefits of physiotherapist directed exercise, reducing falls risk, accountability in maintaining compliance to exercises and improvements in fall-related self-efficacy. Attributes influencing patient satisfaction included: integrated approach of the clinic, programme reliability and useable information and learning.

\section{Factors impacting patient perceived physical benefit}

Participants repeatedly noted improvements in their fall-related self-efficacy. Specifically, participants reported having greater feelings of confidence due to their following the advice received, diagnoses relating to their limitations and information on how to improve or work with these limitations at the Vancouver Falls Prevention Clinic. As a result of this, participants reported being more aware of their limitations, being more careful yet not scared or overpowered by their limitations and actually proceeding to expand their activities of daily living.

Participants also reported feeling a notable reduction in their risk of falling and appreciating the physiotherapist directed exercises. The physiotherapist directed exercises made the participants aware of what and how to do the exercises. Participants noted that the follow-up phone calls were also helpful in ensuring accountability and maintaining compliance to continue with the exercises. Participants reported pain reduction and maintenance or improvements in their mobility as a result of the physiotherapist directed exercises.

\section{Attributes influencing patient satisfaction}

Participants reported several factors that influenced their satisfaction with the clinic. First, they appreciated the integrated approach of the clinic to address multiple problems applicable to the patient as a whole rather than one specific complaint. They also reported positive feelings towards the reliability of the clinic as a place where they could return for follow-up if needed. Lastly, they reported finding the information they received as to what was wrong and how particular health problems might affect their mobility and falls risk. Participants reported being given information in a way that was empowering and useful in terms of their future mobility-related activities (ie, their knowledge of their mobility limitations, their mobility-related confidence and their awareness of physical activity).

\section{DISCUSSION}

Participants attending the Falls Prevention Clinic demonstrated an overall compliance of $69 \%$ to recommendations provided by geriatricians. Participants were most compliant with following through with tests/investigations, medication changes and/or referrals or follow-up appointments. Participants were less compliant with exercise $(58 \%)$ and lifestyle modifications $(35 \%)$. A possible explanation for the lower observed compliance to exercise and lifestyle recommendations may be that both of these require a sustained and long-term change in behaviour.

Existing evidence provides support for the effectiveness of multifactorial falls prevention interventions. ${ }^{6} 8$ Specifically, one multifactorial fall risk and management programme was effective at preventing falls among community-dwelling older adults and demonstrated an $18 \%$ reduction in falls and a $37 \%$ reduction in the rate of falls per person-month. ${ }^{8}$ The feasibility of implementing such strategies in a real-world setting remains limited. To date, only one RCT has ascertained the effectiveness of a physician-led falls clinic in preventing falls and fall-related injuries. This study demonstrated a $26 \%$ reduction in fall-induced injuries and a $22 \%$ reduction in falls among those receiving the falls clinic compared with those who did not. ${ }^{14}$ Another study demonstrated that a comprehensive fall risk assessment combined with follow-up by a registered nurse practitioner in a real-world clinical setting demonstrated a reduction in falls and injurious falls among community-dwelling older adults with a history of falls. ${ }^{13}$ Of the other studies of fall prevention clinics (including one RCT and two uncontrolled trials), up to a $31 \%$ reduction in fall risk was observed and variability in 
Table 2 Description of Vancouver Falls Prevention clinical management advice and compliance ( $n=188$ and 134)

\begin{tabular}{|c|c|c|}
\hline Variable $(n=188)$ & Frequency (\%) & Per cent compliance to recommendation \\
\hline \multicolumn{3}{|c|}{ Requested follow-up } \\
\hline No & $59(31)$ & $78 \%$ \\
\hline Yes & $129(69)$ & \\
\hline \multicolumn{3}{|l|}{ Ordered } \\
\hline 0 & $169(90)$ & \\
\hline 1 & $18(10)$ & $88 \%$ to one or two investigations \\
\hline 2 & $1(0)$ & \\
\hline \multicolumn{3}{|c|}{ Medication changes $(n=188)$} \\
\hline 0 & $115(82)$ & \\
\hline 1 & $63(34)$ & $78 \%$ compliance to medication changes \\
\hline 2 & $8(4)$ & \\
\hline 3 & $1(0)$ & \\
\hline 4 & $1(0)$ & \\
\hline \multicolumn{3}{|l|}{ Exercise } \\
\hline No & $56(30)$ & $58 \%$ fully compliant and $2 \%$ partially compliant \\
\hline Yes & $132(70)$ & \\
\hline \multicolumn{3}{|c|}{ Lifestyle modifications } \\
\hline 0 & $148(73)$ & $35 \%$ fully compliant and $6 \%$ partially compliant \\
\hline 1 & $34(17)$ & \\
\hline 2 & $2(1)$ & \\
\hline 3 & $1(0)$ & \\
\hline
\end{tabular}

Overall average compliance with all clinical management advice $\quad 0.69(0.42)$ or $69 \%(42 \%)$

Variable $(n=134) \quad$ Frequency (\%) Per cent compliance to recommendation

Requested follow-up

\begin{tabular}{lcc} 
No & $113(74)$ & $72 \%$ \\
Yes & $21(16)$ & \\
Ordered tests/investigations & $132(99)$ & $33 \%$ to at least one investigation \\
No & $2(1)$ & \\
Yes & $110(72)$ & $75 \%$ compliance to at least one medication change \\
Medication changes $(n=188)$ & $24(18)$ & \\
No & $85(63 \%)$ & $56 \%$ partially or fully compliant \\
Yes & $49(37 \%)$ & $45 \%$ partially or fully compliant \\
Exercise & $129(96)$ \\
\hline No & $5(4)$ \\
\hline Yes & \\
\hline Lifestyle modifications & \\
\hline Yes &
\end{tabular}

Individuals who received zero recommendations were not included in the denominator count. Overall compliance was estimated as follows: (1) individuals were given 1 point for every recommendation they received; (2) individuals were given 1 point for every recommendation that they complied with; and (3) overall compliance was: number of recommendations complied with/total number of recommendations. The sample of 134 excludes the 54 participants who took part in an intervention-based randomised controlled trial (RCT).

fall risk reduction was attributable in part to the differing baseline falls risk of each of these samples. Of note, none of these include a geriatrician-based model of care. ${ }^{10-13}$
This is one of the key innovations of the clinic described in this study. Hence, while evidence is relatively consistent that multifactorial fall risk management among 
Box 1 Factors influencing patient experience at the Vancouver Falls Prevention Clinic

Factors impacting patient perceived physical benefitFactors impacting patient perceived physical benefit

Improvements in fall-related self-efficacy

'My experience at the falls clinic has been good. I'm still a bit wobbly, but following the advice of the doctors l've been more diligent with the use of my cane and walker and feel more confident in my walking.'

'[The geriatrician] was very attentive. His suggestions were helpful and now I have confidence that my mobility will improve.'

'As a result of the Vancouver Falls Prevention Clinic, I am more careful about what l'm doing. I'm more aware of the need for physical exercises. I'm may not be doing all of the specific exercises that [the geriatrician] had suggested, but I am getting out more. I was raking the lawn this morning and I am taking the stairs all the time now. I don't think I would have attempted to do that or some of the other work I'm doing now if it weren't for [the Vancouver Falls Prevention Clinic]. I was frightened before, but now I'm careful without really being scared. [The geriatrician] really listened to me. He gave me the time, which you don't get a lot of from doctors these days. He really listened. I thought you, as research people, were very kind and straightforward.'

'[My experience with the Vancouver Falls Prevention Clinic] has been very positive. I have never had so much attention paid to my specific needs. I was somewhat overwhelmed by the sheer logistics of the clinic but I made the effort to keep things straight in my mind and straight on the calendar. It does take a lot of time... but it was worth it. There is a sense of confidence I have now. It certainly has impacted my life. I am more confident about the limitations that I do have in that I don't feel overpowered by them. I have discovered a lot of helpful tips and tricks. It's been really very good.'

Reducing falls risk

'The staff was fabulous. I was amazed at how friendly and professional everyone was, including [the geriatrician]. I look forward to beginning physiotherapy to reduce my risk for future falls.'

'It has significantly changed my life. Before coming, stress had been building up for me because I was having all of the falls with no explanations. No one could figure out what was causing my falls. I wasn't able to live my life and do simple day to day tasks without falling or worrying about falling. It makes you feel helpless. After going there my life changed dramatically. I finally felt the ability to move around and just do simple day to day tasks without any stress. A weight has been lifted off my shoulders. My quality of life has changed tremendously. I am aware of my limitations more now and I can be more careful and take things more slowly. I can't speak kindly enough about the effects it has had on me going there. [The geriatrician] is standout, as far as I am concerned. Right from the beginning, the people at work in the clinic are well-trained, concerned, caring, and interested in their jobs. The whole structure of the place is well put together and well organized. There's no waiting time like other clinics. It has done so much for me in a few brief visits.' Accountability in maintaining compliance to exercises

'The follow-up by the clinic helped me stay on track to make sure I was doing the exercises properly. The encouragement that I got to continue with the exercises and the monthly phone calls were all helpful in making sure I didn't give up on the exercises. My balance has improved beyond expectation. I cut my balance risk by half-a big improvement. I am still doing the exercises even after the program has finished. I appreciate the falls clinic more than I can say.'

'My experiences were excellent. Everyone seemed to know their positions. That's why I was willing to be in the research; I had had good experiences. I am more aware now of what I should be doing and what I should not be doing in my own life. I have followed through with my exercises. I go to chair yoga and there is a concentration on balance which I know I need. So I have followed through and that's been good for me.'

Physical benefits of physiotherapist directed exercise

'The exercises also helped reduce the pain in my shoulder.'

'I really appreciated the physiotherapy. It's proven by the clinic; it was shown in the falls risks report, that [the physiotherapy] had a huge impact on my balance. When I first started 6 months ago, my balance was way in the minus group, now l'm actually in the plus group. I've not only gotten back to normal, I'm actually doing better than that. I appreciate having the tests, even the ones I loathe and hate, because they show me that I am not having certain problems, with my brain and that. I try to do them as fast as possible and that, to set a high standard. It's a big plus to know that my brain is active and sharp and everything. I appreciate being able to stay mobile, too. I think that is directly linked to my experience with the physiotherapy and the falls clinic. I obviously have made progress.'

Attributes influencing patient satisfactionAttributes influencing patient satisfaction

Integrated approach of the clinic

'I was very happy with my experiences at the Vancouver Falls Prevention Clinic. I've been very happy with my physician. I appreciate the doctor a whole lot because I feel like he is more of a generalist. He's not a typical specialist-though he is an expert-he sees the whole picture. I felt like the time that he gave me was very fruitful. I am very much for the research you're doing. It makes sense and eventually I think it will really make a difference.'

'At the Falls Clinic I was so well treated, I felt like I was one of them... [The geriatrician] was very encouraging; he was quite upfront and told me everything I needed to know (goes on to describe a specific change in medication on which she was advised by [the geriatrician]).'

'I think it's good to know that they're there... if I had a problem I would know who to address it to. Rather than have it pop up in an emergency... I know the staff and the doctor there I can call them if ever I have any problem and that's better for me, you know than waiting all that time in the emergency or what-have-you, figuring out appointments and all that. I think it's very good.'

'Prior to coming to the falls clinic I was in very bad shape. I was constantly scared of falling down and injuring myself which prevented me from doing many of my usual activities. Fortunately, the physicians at the Vancouver Falls Prevention Clinic are very good. [The geriatrician] in particular! The advice, suggestions and change in medications has overall brought big improvements.'

Programme reliability

'I think that they are very thorough and conscientious at the Falls Clinic. They were knowledgeable and able to help me a great deal. I think that it's a great service. The exercises are a great thing. It is a service I could reliably depend on if I ever needed them again.'

'I think it's good to know that they're there... if I had a problem I would know who to address it to. Rather than have it pop up in an emergency... I know the staff and the doctor there I can call them if ever I have any problem and that's better for me, you know than waiting all that time in the emergency or what-have-you, figuring out appointments and all that. I think it's very good.' 


\section{Box 1 Continued}

Usual information and learning

'The experience at the clinic was very good. It helped a lot and I learned a lot. I learned how to balance and walk better after getting help from a physiotherapist.'

'The recommendations made by the clinic were helpful and the doctor was knowledgeable. My balance is getting worse because my eyesight is getting worse, but it is good to know the reason of these things and why they happen.'

'I feel wonderful about my experiences with the Falls Clinic. I am so grateful to the physiotherapist who referred me. Really, I am so thankful! I really made some changes since going in. Before I went in I was tripping and falling a lot and I thought that was related to age. Now I know that there are a lot of factors that might make me fall and I can be in control of that. I've learned now that I don't have good balance. I always pay attention to that now. I am more careful and cautious. Even when I'm doing things like carrying my groceries, I am very mindful that my balance isn't very good and I take two trips if I need to. When I go to Tai Chi, I had a fall there and the instructors take note of that, I do more of the modified exercises now. I always make sure to have two feet on the ground as much as possible. I stop to look at the situation around me now, whereas before I thought it was just normal and everything was okay. I'm not having so many falls. Because of the program I have been trying to exercise more specifically to do exercises for your legs and your core. I think that is helping, but it's slow.'

older adults at high risk of future falls reduces falls and injurious falls, the literature remains devoid of evaluating a geriatrician-led model of multifactorial assessment and management.

The results of our semistructured interviews also illustrated that factors impacting patient perceived physical benefit included: physical benefits of physiotherapist directed exercise, reducing falls risk, accountability in maintaining compliance to exercises and improvements in fall-related self-efficacy. Research studies have previously demonstrated the relationship with fall-related self-efficacy and balance, mobility, quality of life and brain volume. ${ }^{45-48}$ Several studies have also previously demonstrated the measurable physical benefits of a physiotherapist directed exercise programme. As such, the qualitative data support the quantitative data to date.

The key attributes influencing patient satisfaction included: integrated approach of the clinic, programme reliability and useable information and learning. Researchers have suggested that education is a key component of falls prevention ${ }^{49}$ and it is plausible that the method of delivery of education by the geriatrician in the present study provided benefit to the patients both in terms of fall-related self-efficacy and mobility. One study has also demonstrated high patient satisfaction improvement in activities of daily living and fall reduction with a multidisciplinary falls risk assessment clinic. ${ }^{50}$ Future research should focus on further understanding the mechanism of impact so that we are able to delineate exactly why the observed effects occurred and how that can be replicated. A logical next step would be to conduct a formal process evaluation of the Falls Prevention Clinic to examine: (1) implementation, and (2) mechanisms of impact and context (external factors affecting implementation). ${ }^{51}$

This study has notable strengths. It is a geriatrician-based model of care where the geriatrician bills directly through the provincial Medical Services Plan and as such, this reflects care readily accessible for all individuals meeting the criteria. The exercise recommendations made require minimal equipment and several international studies have demonstrated compliance with this exercise programme among seniors. ${ }^{7} 175253$ Despite the evidence-based merit of a multifactorial approach to falls prevention, ${ }^{9}$ the innovation of this study is to evaluate the feasibility of delivering this type of intervention in a realworld clinical setting among a population at high risk of incurring future falls.

We note the following limitations. One limitation embedded within the real-world setting of the clinic is the comprehensive battery of measures examined which do not replicate current usual care. These measures are clinically relevant and immediately translatable to clinical practice. To address this concern, a next step for research is to determine a minimal set of assessment items (clinical measures) that still provide a comparable reduction in falls and related injury prevention. The Vancouver Falls Prevention Clinic also serves as a platform for research studies. So while the clinic is reflective of a typical urban clinical setting, the compliance data reported may be partially confounded and positively inflated due to a subsample of $25 \%$ receiving the OEP intervention. Geriatricians who served the clinic: (1) were blinded to RCT group allocation; and (2) made recommendations based on the clinical assessments, their expertise and practice guidelines. Thus, an individual in the OEP experimental group may or may not receive exercise recommendations from the geriatrician. Patients who received assessment at the Vancouver Falls Prevention Clinic were not randomised into intervention or control group-everyone received the Falls Prevention Clinic intervention. This was done so as not to deny any individual best practice care guided by the best available evidence. As such, it was impossible to estimate an incidence rate ratio for falls reduction in this study since we lacked a control group. Lastly, the Falls Prevention Clinic only provided service for those who were screened and categorised as high risk for future falls. There is a shortage of geriatricians in Canada; however, Vancouver is an area well serviced by geriatricians. Over the past 5 years, we have had primarily one geriatrician serving $80 \%$ of patients at the Falls Prevention Clinic. This limit was imposed due to a shortage of clinical space. This, combined with the highly selective population, reduced the sample size of this study. 


\section{CONCLUSIONS}

The burden of falls is substantial and the consequences of falls can significantly impact mortality, morbidity, quality of life and economic burden. Our goal was to discover and deliver effective and efficient interventions to prevent falls that can be translated to a population. This study provides initial feasibility and acceptability data using a multifactorial approach based on best available evidencebased medicine.

\section{Author affiliations}

${ }^{1}$ Faculty of Management, University of British Columbia, Vancouver, British Columbia, Canada

${ }^{2}$ Center for Hip Health and Mobility, Faculty of Medicine, University of British Columbia, Vancouver, British Columbia, Canada

${ }^{3}$ Faculty of Medicine, University of British Columbia, Vancouver, British Columbia, Canada

${ }^{4}$ Division of Geriatrics, Faculty of Medicine, University of British Columbia, Vancouver, British Columbia, Canada

${ }^{5}$ Department of Family Practice, Faculty of Medicine, University of British Columbia, Vancouver, British Columbia, Canada

${ }^{6}$ Department of Physical Therapy, University of British Columbia, Vancouver, British Columbia, Canada

${ }^{7}$ Djavad Mowafaghian Centre for Brain Health , Faculty of Medicine, University of British Columbia, Vancouver, British Columbia, Canada

Acknowledgements We thank the Vancouver Falls Prevention cohort study participants. The Canadian Institute for Health Research Emerging Team Grant (CIHR, MOB-93373 to TLA) provided funding for this study. TLA is a Canada Research Chair in Physical Activity, Mobility, and Cognitive Neuroscience, a Michael Smith Foundation for Health Research (MSFHR) scholar, a Canadian Institutes of Health Research (CIHR) new investigator, and a Heart and Stroke Foundation of Canada's Henry JM Barnett Scholarship recipient. JCD and JB were funded by a CIHR and MSFHR Postdoctoral Fellowship at the onset of this study.

Contributors TLA was the principal investigator for the Vancouver Falls Prevention Clinic cohort study. JCD and TLA were responsible for study concept and design, acquisition of data, data analysis and interpretation, and writing and reviewing of the manuscript. JCD was responsible for data analysis. JCD, NP, KM, KMK, WCa, WCe, JR and TLA drafted and revised the manuscript. JCD, TLA, NP, KM, WCa, WCe, $J R$ and $L D$ acquired and interpreted the data.

Funding The authors have not declared a specific grant for this research from any funding agency in the public, commercial or not-for-profit sectors.

Competing interests None declared.

Patient consent Not required.

Ethics approval Vancouver Coastal Health Research Institute and the University of British Columbia's Clinical Research Ethics Board (H09-02370).

Provenance and peer review Not commissioned; externally peer reviewed.

Data sharing statement Please contact teresa.ambrose@ubc.ca for any data sharing requests.

Open access This is an open access article distributed in accordance with the Creative Commons Attribution Non Commercial (CC BY-NC 4.0) license, which permits others to distribute, remix, adapt, build upon this work non-commercially, and license their derivative works on different terms, provided the original work is properly cited, appropriate credit is given, any changes made indicated, and the use is non-commercial. See: http://creativecommons.org/licenses/by-nc/4.0/.

\section{REFERENCES}

1. Inouye SK, Studenski S, Tinetti ME, et al. Geriatric syndromes: Clinical, research, and policy implications of a core geriatric concept. (see editorial comments by dr. William hazzard on pp 794-796). J of the Amer Geriatrics Society 2007;55:780-91.

2. Murray C, Lopez A. Global and regional descriptive epidemiology of disability: Incidence, prevalence, health expectancies, and years lived with disability. In: Murray C, Lopez A, eds. The global burden of disease. Boston: The Harvard School of Public Health, 1996:201-46.

3. Grossman DC, Curry SJ, Owens DK, et al. US Preventive Services Task Force. Interventions to Prevent Falls in Community-Dwelling Older Adults: US Preventive Services Task Force Recommendation Statement. JAMA 2018;319:1696-704.

4. Stevens JA, Lee R. The potential to reduce falls and avert costs by clinically managing fall risk. Am J Prev Med 2018;55:290-7.

5. Gillespie L. Preventing falls in older people: the story of a Cochrane review. Cochrane Database Syst Rev 2013;2:ED000053.

6. Gillespie LD, Robertson MC, Gillespie WJ, et al. Interventions for preventing falls in older people living in the community. Cochrane Database Syst Rev 2012;9:CD007146.

7. Davis JC, Robertson MC, Ashe MC, et al. Does a home-based strength and balance programme in people aged $>$ or $=80$ years provide the best value for money to prevent falls? A systematic review of economic evaluations of falls prevention interventions. $\mathrm{Br} \mathrm{J}$ Sports Med 2010;44:80-9.

8. Chang JT, Morton SC, Rubenstein LZ, et al. Interventions for the prevention of falls in older adults: systematic review and metaanalysis of randomised clinical trials. BMJ 2004;328:680.

9. Close J, Ellis M, Hooper R, et al. Prevention of falls in the elderly trial (PROFET): a randomised controlled trial. Lancet 1999;353:93-7.

10. Emmelot-Vonk MH, Verhaar HJ. [The effectiveness of falls clinics in the Netherlands]. Tijdschr Gerontol Geriatr 2011;42:113-7.

11. Hill KD, Moore KJ, Dorevitch MI, et al. Effectiveness of falls clinics: an evaluation of outcomes and client adherence to recommended interventions. J Am Geriatr Soc 2008;56:600-8.

12. Lord SR, Tiedemann A, Chapman K, et al. The effect of an individualized fall prevention program on fall risk and falls in older people: a randomized, controlled trial. J Am Geriatr Soc 2005;53:1296-304

13. Moore M, Williams B, Ragsdale S, et al. Translating a multifactorial fall prevention intervention into practice: a controlled evaluation of a fall prevention clinic. J Am Geriatr Soc 2010;58:357-63.

14. Palvanen M, Kannus P, Piirtola M, et al. Effectiveness of the chaos falls clinic in preventing falls and injuries of home-dwelling older adults: a randomised controlled trial. Injury 2014;45:265-71.

15. de Vries OJ, Peeters GM, Elders PJ, et al. Multifactorial intervention to reduce falls in older people at high risk of recurrent falls: a randomized controlled trial. Arch Intern Med 2010;170:1110-7.

16. Liu-Ambrose T, Davis JC, Hsu CL, et al. Action seniors! - secondary falls prevention in community-dwelling senior fallers: study protocol for a randomized controlled trial. Trials 2015;16:144.

17. Campbell AJ, Robertson MC, La Grow SJ, et al. Randomised controlled trial of prevention of falls in people aged $>$ or $=75$ with severe visual impairment: the VIP trial. BMJ 2005;331:817.

18. Davis JC, Best JR, Bryan S, et al. Mobility Is a key predictor of change in well-being among older adults who experience falls: evidence from the vancouver falls prevention clinic cohort. Arch Phys Med Rehabil 2015;96:1634-40.

19. Davis JC, Bryan S, Best JR, et al. Mobility predicts change in older adults' health-related quality of life: evidence from a Vancouver falls prevention prospective cohort study. Health Qual Life Outcomes 2015;13:101.

20. Kellogg International Work Group. The prevention of falls in later life. A report of the kellogg international work group on the prevention of falls by the elderly. Dan Med Bull 1987;34 Suppl 4:1-24.

21. Guralnik JM, Ferrucci L, Simonsick EM, et al. Lower-extremity function in persons over the age of 70 years as a predictor of subsequent disability. N Engl J Med 1995;332:556-62.

22. Shumway-Cook A, Brauer S, Woollacott M. Predicting the probability for falls in community-dwelling older adults using the timed up \& go test. Phys Ther 2000;80:896-903.

23. Lord SR, Clark RD, Webster IW. Physiological factors associated with falls in an elderly population. J Am Geriatr Soc 1991;39:1194-200.

24. Lord SR, Ward JA, Williams $P$, et al. Physiological factors associated with falls in older community-dwelling women. J Am Geriatr Soc 1994;42:1110-7.

25. Delbaere K, Close JC, Brodaty $\mathrm{H}$, et al. Determinants of disparities between perceived and physiological risk of falling among elderly people: cohort study. BMJ 2010;341:c4165.

26. Folstein MF, Folstein SE, McHugh PR. "Mini-mental state". A practical method for grading the cognitive state of patients for the clinician. J Psychiatr Res 1975;12:189-98.

27. Nasreddine ZS, Phillips NA, Bédirian V, et al. The Montreal Cognitive Assessment, MoCA: a brief screening tool for mild cognitive impairment. J Am Geriatr Soc 2005;53:695-9.

28. Rapport LJ, Webster JS, Flemming KL, et al. Predictors of falls among right-hemisphere stroke patients in the rehabilitation setting. Arch Phys Med Rehabil 1993;74:621-6. 
29. Rapport LJ, Hanks RA, Millis SR, et al. Executive functioning and predictors of falls in the rehabilitation setting. Arch Phys Med Rehabil 1998;79:629-33.

30. Lord SR, Fitzpatrick RC. Choice stepping reaction time: a composite measure of falls risk in older people. J Gerontol A Biol Sci Med Sci 2001;56:M627-M632.

31. Lundin-Olsson L, Nyberg L, Gustafson Y. "Stops walking when talking" as a predictor of falls in elderly people. Lancet 1997;349:617.

32. Anstey KJ, von Sanden C, Luszcz MA. An 8-year prospective study of the relationship between cognitive performance and falling in very old adults. J Am Geriatr Soc 2006;54:1169-76.

33. Nevitt MC, Cummings SR, Hudes ES. Risk factors for injurious falls: a prospective study. J Gerontol 1991;46:M164-M170.

34. Graf P, Uttl B, Tuokko H. Color- and picture-word Stroop tests: performance changes in old age. J Clin Exp Neuropsychol 1995;17:390-415.

35. Spreen O, Strauss EA. Compendium of neuropsychological tests. 2nd edn, 1998.

36. Salthouse TA. Evaluating the correspondence of different cognitive batteries. Assessment 2014;21:131-42.

37. Groll DL, To T, Bombardier C, et al. The development of a comorbidity index with physical function as the outcome. J Clin Epidemiol 2005;58:595-602.

38. Lawton MP, Brody EM. Assessment of older people: selfmaintaining and instrumental activities of daily living. Gerontologist 1969;9:179-86.

39. Yesavage JA. Geriatric depression scale. Psychopharmacol Bull 1988;24:709-11.

40. Yesavage JA, Brink TL, Rose TL, et al. Development and validation of a geriatric depression screening scale: a preliminary report. $J$ Psychiatr Res 1982;17:37-49.

41. van Marwijk HW, Wallace $P$, de Bock $\mathrm{GH}$, et al. Evaluation of the feasibility, reliability and diagnostic value of shortened versions of the geriatric depression scale. Br J Gen Pract 1995;45:195-9.
42. Sherrington C, Lord SR, Vogler CM, et al. A post-hospital home exercise program improved mobility but increased falls in older people: a randomised controlled trial. PLoS One 2014;9:e104412.

43. Davis JC, Hsu CL, Cheung W, et al. Can the Otago falls prevention program be delivered by video? A feasibility study. BMJ Open Sport Exerc Med 2016;2:e000059.

44. Carpenter C, Suto M. Qualitative Research for Occupational and Physical Therapists: A Practical Guide: Wiley-Blackwell, 2008. ISBN: 978-1-405-14435-3.

45. Davis JC, Marra CA, Liu-Ambrose TY. Falls-related self-efficacy is independently associated with quality-adjusted life years in older women. Age Ageing 2011;40:340-6.

46. Davis JC, Nagamatsu LS, Hsu CL, et al. Self-efficacy is independently associated with brain volume in older women. Age Ageing 2012;41:495-501.

47. Liu-Ambrose T, Davis JC, Nagamatsu LS, et al. Changes in executive functions and self-efficacy are independently associated with improved usual gait speed in older women. BMC Geriatr 2010;10:25

48. Liu-Ambrose T, Khan KM, Donaldson MG, et al. Falls-related selfefficacy is independently associated with balance and mobility in older women with low bone mass. J Gerontol A Biol Sci Med Sci 2006;61:832-8.

49. Wolf-Klein GP, Silverstone FA, Basavaraju N, et al. Prevention of falls in the elderly population. Arch Phys Med Rehabil 1988;69:689-91.

50. Perell KL, Manzano ML, Weaver R, et al. Outcomes of a consult fall prevention screening clinic. Am J Phys Med Rehabil 2006;85:882-8.

51. Moore GF, Audrey S, Barker M, et al. Process evaluation of complex interventions: medical research council guidance. BMJ 2015;350:h1258

52. Campbell AJ, Robertson MC, Gardner MM, et al. Randomised controlled trial of a general practice programme of home based exercise to prevent falls in elderly women. BMJ 1997;315:1065-9.

53. Liu-Ambrose T, Donaldson MG, Ahamed Y, et al. Otago home-based strength and balance retraining improves executive functioning in older fallers: a randomized controlled trial. J Am Geriatr Soc 2008;56:1821-30. 